\title{
Detecting Informed Trading Activities in the Options Markets
}

\author{
Marc Chesney* \\ Remo Crameri ${ }^{\dagger}$ \\ Loriano Mancini ${ }^{\ddagger}$ \\ University of Zurich and \\ UBS AG \\ EPFL and \\ Swiss Finance Institute \\ Swiss Finance Institute
}

April 7, 2014

\footnotetext{
*Corresponding author: Marc Chesney, University of Zurich, Department of Banking and Finance, Plattenstrasse 32, CH-8032 Zurich, Switzerland. Telephone: +41 (0)44 6344580 . Fax: +41 (0)44 6344903. E-mail: marc.chesney@bf.uzh.ch.

†UBS AG, Stockerstrasse 64, P.O. Box 8092, Zurich, Switzerland. E-mail: remo.crameri@ubs.ch.

$\ddagger$ EPFL, Swiss Finance Institute at EPFL, Quartier UNIL-Dorigny, Extranef 217, CH-1015 Lausanne, Switzerland. E-mail: loriano.mancini@epfl.ch.
} 


\title{
Detecting Informed Trading Activities in the Options Markets
}

\begin{abstract}
We develop a statistical approach to detect informed trades in options markets. The method is applied to 9.6 million of daily option prices. Empirical results suggest that option informed trades tend to cluster prior to certain events, generate easily large gains exceeding millions, are not contemporaneously reflected in the underlying stock price, and involve liquid options during calm times and cheap options during turbulent times. These findings are not driven by false discoveries in informed trades which are controlled using a multiple hypothesis testing technique. Pricing, policy, and market efficiency implications of these findings are discussed.
\end{abstract}

Keywords: Massive dataset, False Discovery Rate, Options Trades, Open Interest, Informed Trading

JEL Classification: G12, G13, G14, G17 


\section{Introduction}

Informed trading activities play a key role in financial markets. Asset prices will eventually reflect relevant information because of trading activities of informed investors. This is important because virtually any financial activity, such as investment decisions, capital allocations or risk measurements, is affected by current asset prices, which should reflect the fundamental values of the assets. While the existence of informed trading is well documented in the empirical literature, very little is known about the characteristics of informed trades. The goal of this paper is to provide a detail analysis in order to understand when option informed trading happens, under what circumstances, and which options are involved.

We develop two statistical methods to detect option informed trades. The first method uses only ex-ante information and aims to detect option informed trades as soon as they take place. We look for option trades characterized by unusually large increments in open interest, i.e., number of outstanding contracts, which are close to daily trading volumes. In those cases the originator of such transactions is not interested in intraday speculations but has reasons for keeping her position for a longer period. Applying this simple rule to our dataset, we find that the higher the increment in open interest and volume the higher the future return of the corresponding option. This finding is consistent with informed traders being the originators of the large increments in open interest and volume. An important question is whether truly informed investors or simply lucky traders were behind those large gains. To answer this question we develop a formal test based on multiple hypothesis testing techniques to control for false discoveries. We refine the first method using a nonparametric test to check whether those option trades are hedged with the underlying asset or used for 
hedging purposes. Our second method to detect option informed trading uses also ex-post information and encompasses the first method by adding an additional criterion. An option trade is identified as informed when the increment in open interest and volume is unusual, not hedged (as in the first method), and generates large option gains.

Our approach to detect option informed trading is different from previous methods in at least two dimensions: it controls for false discoveries in informed trades and accounts for option hedging. Addressing these issues is a challenging task. In any statistical method, the probability that an uninformed option trade will appear to be informed simply by chance is not zero. This misclassification is induced by the Type I error in hypothesis testing, as the test of option informed trade is repeated each day. However, this misclassification error can be formally quantified using multiple hypothesis testing techniques. Intuitively, uninformed option traders should achieve zero return on average, while informed traders should enjoy statistically large returns. Under the null hypothesis that all traders are uninformed, the proportion of lucky traders depends on the size of the test and can be calculated using option returns. When the difference between the actual fraction of large returns (due to informed and lucky traders) and the expected fraction of large returns due to lucky traders is statistically large, the test rejects the null hypothesis that all traders are uninformed. We also estimate the fraction of truly informed options traders.

We develop a nonparametric test to assess whether option hedging takes place or not. For example, when studying long positions in call options, the idea is to decompose the underlying stock seller-initiated trading volume in the hedging and non-hedging components. This decomposition is achieved using the theoretical amount of stock trading which would have been generated if no option informed trading would have occurred. Then the test rejects 
the null hypothesis of absence of hedging when the hedging component is statistically large.

We undertake an extensive empirical analysis of option informed trading. We apply the two statistical methods to 9.6 million of daily options prices of 31 selected companies mainly from airline, banking and insurance sectors. Several millions of intraday stock price and volume data are also analyzed to assess whether an option trade is hedged or not. The sample period spans 14 years, from January 1996 to September 2009 (the first part of our sample ends in April 2006), and our analysis is at the level of individual option, rather than on the cross-section of stock returns. ${ }^{1}$

Our main empirical findings are summarized as follows. First, detected option informed trades tend to cluster prior to certain events such as merger or acquisition announcements (M\&A), quarterly financial or earning related statements, the terrorist attacks of September 11th, and first announcements of financial disruptions of banking and insurance companies during the Subprime financial crisis 2007-2009. We note that only undertaking an extensive empirical analysis this finding could emerge. Second, prior to a particular event which will impact a particular company, informed trading can involve more than one option but rarely the cheapest option, i.e., deep out-of-the-money and with shortest maturity. This finding is consistent with informed investors trading fairly liquid options and attempting not to immediately reveal their private signals. We detect informed trades in cheap options mainly during the Subprime crisis prior to financial disruption announcements. Third, the majority of detected informed trades take place in put rather than call options. This finding has to

\footnotetext{
${ }^{1}$ As mentioned above, we rely on statistical methods to detect option informed trades. Therefore, those trades will be informed only with a certain probability. For brevity, we refer to those trades simply as option informed trades. Moreover, detected informed trades might or might not be legal. From a legal viewpoint this study does not constitute proof per se of illegal activities. Legal proof would require trader identities and their motivations, information which is not contained in our dataset.
} 
be cautiously interpreted as corporate insiders may use put options to hedge human capital risk. ${ }^{2}$ Fourth, estimated option gains of informed traders easily exceed several millions for a single event. Those gains are likely to be realized as they correspond to actual trades. Finally, the underlying stock price does not display any particular behavior on the day of the detected option informed trade. Only some days later, for example when a negative company news is released, the stock price drops generating large gains in long put positions. Although we use publicly available data to detect option informed trading, it appears that the information content of such trading is not contemporaneously impounded into the underlying stock price.

As an example, our statistical method detects four informed put option trades on EUREX between April and June 2006 with the underlying being EADS, the parent of plane maker Airbus. These trades precede the June 14th, 2006 announcement that deliveries of the superjumbo jet A380 would be delayed by a further six months period, causing a $26 \%$ fall in the underlying stock, and a total gain of approximately $€ 8.7$ million in these option trades.

Some economists even view insider trading as informed trading and argue that laws making insider trading illegal should be revoked. Milton Friedman, laureate of the Nobel Memorial Prize in Economics, said: "You want more insider trading, not less. You want to give the people most likely to have knowledge about deficiencies of the company an incentive to make the public aware of that." Friedman believed that any constraint to informed traders should be removed and that buying or selling pressure is sufficient to impound new

\footnotetext{
${ }^{2}$ Human capital is defined as the sum of the present value of the future cash income, shares, stock options, etc., and it represents the most significant risk faced by corporate insiders especially senior managers. To the extent it is legal, a long put option is probably the only liquid instrument that can be used by corporate insiders to hedge the risk attached to their human capital. As information about trading behaviors of individual corporate insiders is not available, we cannot disentangle whether put option trades are due to informed traders or corporate insiders hedging their human capital. Human capital risk does not affect informed trading in call options.
} 
information into asset prices. While this phenomenon may occur in stock markets, our findings suggest that it does not take place in the options markets.

The paper is organized as follows. Section 2 reviews the related literature on informed trading. Section 3 introduces our method to detect option informed trades. Section 4 describes the dataset. Section 5 presents the empirical results. Section 6 quantifies false discoveries in option informed trades. Section 7 discusses various robustness checks. Section 8 concludes.

\section{Related Literature}

Several studies have documented informed trading activities both in stock and option markets; see, e.g., Hasbrouck (1991), Easley and O’Hara (1992), Easley, O’Hara, and Srinivas (1998), Poteshman (2006), and Boulatov, Hendershott, and Livdan (2012). Keown and Pinkerton (1981) report statistical evidence of (illegal) informed stock trading up to 12 days before the first public announcement of a proposed merger. Christophe, Ferri, and Angel (2004) document abnormal short-selling before scheduled corporate earnings announcements. Lee, Mucklow, and Ready (1993) provide related evidence studying bid-ask spreads and market depths. However, as discussed in Grossman (1977), Diamond and Verrechia (1987), and others, option markets offer significant advantages to informed traders as opposed to stock markets. Options provide potential downside protection, an alternative way of short selling when shorting stocks is expensive or forbidden, additional leverage which might not be possible in stock or bond markets (Biais and Hillion (1994)), and possibly more discreetness for trading on private signals. Indeed, Cao, Chen, and Griffin (2005) show that call-volume im- 
balances prior to unscheduled takeover announcements are strongly related to stock returns on the announcement day. Pan and Poteshman (2006) report clear evidence that option trading volumes predict future price changes. Bali and Hovakimian (2009) show that the difference between realized and implied volatilities of individual stocks predicts the crosssectional variation of expected returns. Cremers and Weibaum (2010) find that deviations from put-call parity contain information about future stock returns. Yan (2011) documents a negative relation between the slope of implied volatility smile and stock return. In these studies (and others), the analysis is systematically conducted at an aggregate level, e.g., extracting information from all current option prices, and cannot clarify the characteristics of the individual informed trades, which is the aim of this paper.

Our paper is also related to the literature dealing with linkages of information between option and stock markets; see, e.g., Pan and Poteshman (2006), Lakonishok, Lee, Pearson, and Poteshman (2007), and Gârleanu, Pedersen, and Poteshman (2009). Our contribution is to clarify under which conditions such linkages occur, such as which corporate announcements or out-of-the-money option trading precede informed trading activities.

Stephan and Whaley (1990), Chan, Chung, and Johnson (1993), Manaster and Rendleman (1982), and Lee and Yi (2001), among others, discuss why informed traders may consider options as superior trading vehicles. Our results show that option markets can offer significant profits to informed traders, lending empirical support to these studies. Chen, Hong, and Stein (2001) show that asset crashes can be predicted using shares trading volume. We complement this work by showing that certain increments in trading volume and open interest have predictive power for future movements in the underlying stock. Blume, Easley, and O'Hara (1994) and Vijh (1990) provide related studies on trading volume and 
information-related trading.

\section{Detecting Option Informed Trades}

We propose two methods to detect option informed trades. The first method relies on a broad but empirically successful definition of informed trade, based on open interest and volume, and makes use only of ex-ante information. The second method is based on a more stringent definition of option informed trade and uses ex-post information as well.

We now describe the second method with the first method being a special case. We define an option informed trade as follows: $C_{1}$ ) an unusual trade in an option contract, $C_{2}$ ) which is made a few days before the occurrence of a specific event and generates large gains in the following days, and $C_{3}$ ) the position is not hedged in the stock market and not used for hedging purposes. These three characteristics, $C_{i}, i=1,2,3$, lead to the following method to detect informed trading activities in options markets: first on each day the option contract with largest increment in open interest (i.e., number of outstanding contracts) and volume is identified, then the rate of return and dollar gain generated by this transaction are calculated, and finally it is studied whether hedging occurs. Options trades which are delta hedged or used for hedging purposes are not regarded as informed trades. The first method relies only on characteristics $C_{1}$ and $C_{3}$, and their practical implementation. Importantly,

both methods require only commonly available datasets and thus can be easily applied to detect option informed trades in various settings.

Other definitions of informed trading are probably conceivable, as informed traders can undertake various trading activities with different degrees of complexity, splitting their orders 
or jamming their private signals. In this paper we restrict our attention to the economically sensible informed trade characterized by $C_{i}, i=1,2,3$, above. Beside the clear interpretation, this definition of informed trade is amenable to an empirical analysis with publicly available data.

We now explain how to detect informed trades in call options. The application to put options can easily be deduced. In the empirical section, we apply both methods to a large dataset of call and put options.

\subsection{First Criterion: Increment in Open Interest Relative to Volume}

For every call option $k$ available at day $t$ we compute the difference $\Delta O I_{t}^{k}:=O I_{t}^{k}-O I_{t-1}^{k}$, where $O I_{t}^{k}$ is its open interest at day $t$ and $:=$ means defined as. When the option does not exist at time $t-1$, its open interest is set to zero. Since we are interested in unusual transactions, only the option with the largest increment in open interest is considered

$$
X_{t}:=\max _{k \in K_{t}} \Delta O I_{t}^{k}
$$

where $K_{t}$ is the set of all call options available at day $t$. The motivation for using open interest is the following. Large trading volumes can emerge under various scenarios for example when the same call option is traded several times during the day or large sell orders are executed. In contrast large increments in open interest are usually originated by large buy orders. These increments also imply that other long investors are unwilling to close their positions forcing the dealer or market maker to issue new call options. Consequently, we use large increment in open interest as a proxy for large buy orders. 
We focus on transactions for which the corresponding volume almost coincides with the increment in open interest. Let $V_{t}$ denote the daily trading volume corresponding to the call option selected in (1). The positive difference $Z_{t}:=\left(V_{t}-X_{t}\right)$ provides a measure of how often the newly issued options are exchanged: the smaller the $Z_{t}$, the less the new options are traded during the day on which they are created. In that case the originator of such transactions is not interested in intraday speculations but has reasons for keeping her position for a longer period possibly waiting for the realization of future events.

This first criterion already allows us to identify single transactions as potential candidates for informed trades. Let $q_{t}$ denote the ex-ante joint historical probability of observing unusual large increment in open interest close to the trading volume

$$
q_{t}:=\mathbb{P}\left[X \geq X_{t}, Z \leq Z_{t}\right]=\frac{1}{N} \sum_{i=1}^{N} \mathbf{1}_{\left\{X_{i} \geq X_{t}, Z_{i} \leq Z_{t}\right\}}
$$

where $\mathbb{P}$ denotes the empirical probability, $N$ the length of the estimation window, e.g., $N=500$ trading days, and $\mathbf{1}_{\{A\}}=1$ when the event $A$ occurs, and zero otherwise. By construction, low values of $q_{t}$ suggest that these transactions were unusual. For example when $q_{t}=1 / N$, it means that what occurred on day $t$ has no precedents in the previous two years.

\subsection{Second Criterion: Relative Return and Realized Gain}

The second criterion takes into consideration the ex-post returns and realized gains from transactions with a low ex-ante probability $q_{t}$. For each day $t$ the trade with the largest increment in open interest is considered. Let $r_{t}^{\max }$ denote the maximum option return gen- 
erated in the following two trading weeks

$$
r_{t}^{\max }:=\max _{j=1, \ldots, 10} \frac{P_{t+j}-P_{t}}{P_{t}}
$$

where $P_{t}$ denotes the mid-quote price of the selected call option at day $t$. When $r_{t}^{\max }$ is unusually high, an unusual event occurs during the two trading weeks.

For the computation of realized gains, we consider decrements in open interest, $\Delta O I_{t}^{k}$, which occur when exercising or selling to the market maker the call option. ${ }^{3}$ Then we set the American call option value to its exercise value, which is true in most cases. Given our definition of informed trade, it is quite likely that on the event day the rise in the stock price is large enough to reach the exercise region. If options are sold rather than exercised, our calculation of realized gains may underestimate the actual gains. Hence reported gains should be interpreted in a conservative manner. For brevity, we refer to decrement in open interest as option exercise. Also, we omit the superscript $k$ and whenever we refer to a specific option we mean the one which was selected because of its largest increment in open interest close to trading volume, i.e., lowest ex-ante probability $q_{t}$.

Let $G_{t}$ denote the corresponding cumulative gains achieved through the exercise of options

$$
G_{t}:=\sum_{\tilde{t}=t+1}^{\tau_{t}}\left(\left(S_{\tilde{t}}-K\right)^{+}-P_{t}\right)\left(-\Delta O I_{\tilde{t}}\right) \mathbf{1}_{\left\{\Delta O I_{\tilde{t}}<0\right\}}
$$

where $\tau_{t}$ is such that $t<\tau_{t} \leq T$, with $T$ being the maturity of the selected option. If the call options were optimally exercised (i.e., as soon as the underlying asset $S_{\tilde{t}}$ touches the

\footnotetext{
${ }^{3} \mathrm{On}$ a given day, opening new positions (which increases open interest) and closing existing positions (which decreases open interest) can off-set each other. Hence the observed decrement in open interest is a lower bound for actual exercised or sold options.
} 
exercise region), the payoff $\left(S_{\tilde{t}}-K\right)^{+}$corresponds to the price of the option at time $\tilde{t}$.

The cumulative gains $G_{t}$ could be easily calculated for every $\tau_{t} \leq T$. This has however the disadvantage that $G_{t}$ could include gains which are realized through the exercise of options which were issued before time $t .{ }^{4}$ To avoid this inconsistency, the time $\tau_{t}$ is defined as follows

$$
\begin{aligned}
\tau_{t}^{*} & :=\arg \max _{l \in\{t+1, \ldots, T\}}\left(\sum_{\tilde{t}=t+1}^{l}\left(-\Delta O I_{\tilde{t}}\right) \mathbf{1}_{\left\{\Delta O I_{\tilde{t}}<0\right\}} \leq X_{t}\right) \\
\tau_{t} & :=\min \left(\tau_{t}^{*}, 30\right)
\end{aligned}
$$

giving the informed trader no more than 30 days to collect her gains. In general the sum of negative decrements in open interest till time $\tau_{t}$ will be smaller than the observed increment in open interest $X_{t}$. In that case, we will add to $G_{t}$ the gains realized through the fraction of the next decrement in open interest. Hence the sum of all negative decrements in open interest will be equal to the increment $X_{t}$.

Calculating $G_{t}$ for each day $t$ and each option in our database provides information on whether or not option trades with a low ex-ante probability $q_{t}$ generate large gains through exercise. Using the maximal return $r_{t}^{\max }$ in (3), we can calculate the time- $t$ ex-post joint historical probability $p_{t}$ of the event $\left\{X_{t}, Z_{t}, r_{t}^{\max }\right\}$

$$
p_{t}:=\mathbb{P}\left[X \geq X_{t}, Z \leq Z_{t}, r^{\max } \geq r_{t}^{\max }\right]=\frac{1}{N} \sum_{i=1}^{N} \mathbf{1}_{\left\{X_{i} \geq X_{t}, Z_{i} \leq Z_{t}, r_{i}^{\max } \geq r_{t}^{\max }\right\}}
$$

The probability $\left(1-p_{t}\right)$ can be interpreted as a proxy for the probability of informed trading

\footnotetext{
${ }^{4}$ Consider for example an option which exhibits an unusually high increment in open interest at time $t$, say $O I_{t-1}=1,000$ and $O I_{t}=3,000$ resulting in $X_{t}:=O I_{t}-O I_{t-1}=2,000$. Suppose that in the days following this transaction the level of open interest decreases and after $h$ days reaches the level $O I_{t+h}=500$. One should only consider the gains realized through exercise till time $\tau_{t} \leq t+h$, where $\tau_{t}$ is such that the sum of negative decrements in open interest during $\left[t+1, \tau_{t}\right]$ equals $X_{t}=2,000$.
} 
in the option market. The higher $\left(1-p_{t}\right)$ the larger the option return and the more unusual the increment in open interest close to trading volume.

\subsection{Third Criterion: Hedging Option Position}

Option trades for which the first two criteria show abnormal behavior cannot be immediately classified as informed trading. It could be the case that such transactions were hedged by traders using the underlying asset. Without knowing the exact composition of each trader's portfolio, it is not possible to assess directly whether each option trade was hedged or not.

We attempt to assess indirectly whether unusual trades in call options are actually delta hedged using the underlying asset. The idea is to compare the theoretical total amount of shares sold for non-hedging purposes and the actual total volume of seller-initiated transactions in the underlying stock. If the latter is significantly larger than the former, then it is likely that some of the sell-initiated trades occur for hedging purposes. In the opposite case we conclude that the new option positions are not hedged.

One difficulty is that the volume due to hedging is typically a small component of the total seller-initiated volume. Usually, when hedging occurs, newly issued options are hedged on the same day which is our working assumption. Hedging analyses at the level of single option are not possible using our OptionMetrics database. We therefore check whether all the newly issued options are hedged on a specific day $t$. Given our definition of informed option trades, such trades certainly account for a large fraction of the newly issued options.

For each day $t$, the total trading volume of the underlying stock is divided into sellerand buyer-initiated using intraday volumes and transaction prices according to the Lee and 
Ready (1991) algorithm. ${ }^{5}$ Then the seller-initiated volume of underlying stock, $V_{t}^{\text {sell }}$, is divided into trading volume due to hedging and to non-hedging purposes, $V_{t}^{\text {sell,hedge }}$ and $V_{t}^{\text {sell,non-hedge }}$, respectively. Let $\Delta_{t}^{C, k}$ be the delta of call option $k$ and $K_{t}^{C}$ be the set of call options (newly issued or already existing) on day $t$. Similarly for $\Delta_{t}^{P, k}$ and $K_{t}^{P}$. Let

$$
\begin{gathered}
\alpha_{t}:=\sum_{k \in K_{t}^{C}}\left|O I_{t}^{C, k}-O I_{t-1}^{C, k}\right|\left|\Delta_{t}^{C, k}\right|, \quad \gamma_{t}:=\sum_{k \in K_{t}^{P}}\left|O I_{t}^{P, k}-O I_{t-1}^{P, k}\right| \Delta_{t}^{P, k}, \\
\beta_{t}:=\sum_{k \in K_{t}^{C}}\left|\Delta_{t}^{C, k}-\Delta_{t-1}^{C, k}\right| O I_{t-1}^{C, k}, \quad \delta_{t}:=\sum_{k \in K_{t}^{P}}\left|\Delta_{t}^{P, k}-\Delta_{t-1}^{P, k}\right| O I_{t-1}^{P, k} .
\end{gathered}
$$

The $\alpha_{t}$ and $\gamma_{t}$ represent the theoretical number of shares to sell for hedging the new call options issued at day $t$, whereas $\beta_{t}$ and $\delta_{t}$ are the theoretical number of shares to sell to rebalance the portfolio of existing options at day $t$. Absolute changes in open interests and deltas account for the fact that each option contract has a long and short side that follow opposite trading strategies if hedging occurs. The theoretical seller-initiated volume of stock at day $t$ for hedging purposes is $V_{t}^{\text {sell,hedge-theory }}:=\alpha_{t}+\beta_{t}+\gamma_{t}+\delta_{t}$.

When the first two criteria of our method do not signal any informed trade, we approximate $V_{t}^{\text {sell,hedge }}$ by $V_{t}^{\text {sell,hedge-theory }}$. Then the amount of stock sold for non-hedging purposes is calculated as $V_{t}^{\text {sell,non-hedge }}=V_{t}^{\text {sell }}-V_{t}^{\text {sell,hedge-theory }}$.

When informed option trades take place on day $i, V_{i}^{\text {sell,non-hedge }}$ cannot be computed as in the last equation because $V_{i}^{\text {sell,hedge-theory }}$ would be distorted by the unhedged option informed

\footnotetext{
${ }^{5}$ The algorithm states that a trade with a transaction price above (below) the prevailing quote midpoint is classified as a buyer- (seller-) initiated trade. A trade at the quote midpoint is classified as seller-initiated if the midpoint moved down from the previous trade (down-tick), and buyer-initiated if the midpoint moved up (up-tick). If there was no movement from the previous price, the previous rule is successively applied to several lags to determine whether a trade was buyer- or seller-initiated.
} 
trades. We circumvent this issue by forecasting the volume $V_{i}^{\text {sell,non-hedge }}$ on day $i$ using historical data on $V_{t}^{\text {sell,non-hedge }}$. The conditional distribution of $V_{i}^{\text {sell,non-hedge }}$ is estimated using the adjusted Nadaraya-Watson estimator and the bootstrap method proposed by Hall, Wolff, and Yao (1999)

$$
\tilde{F}(y \mid \mathbf{x})=\frac{\sum_{t=1}^{T} \mathbf{1}_{\left\{Y_{t} \leq y\right\}} w_{t}(\mathbf{x}) K_{\mathbf{H}}\left(\mathbf{X}_{t}-\mathbf{x}\right)}{\sum_{t=1}^{T} w_{t}(\mathbf{x}) K_{\mathbf{H}}\left(\mathbf{X}_{t}-\mathbf{x}\right)}
$$

with $Y_{t}:=V_{t}^{\text {sell,non-hedge }}, \mathbf{X}_{t}:=\left(\left|r_{t}\right|, V_{t-1}^{\text {sell,non-hedge }}\right), K_{\mathbf{H}}($.$) being a multivariate kernel with$ bandwidth matrix $\mathbf{H}, w_{t}(\mathbf{x})$ the weighting function, and $r_{t}$ the stock return at day $t$; we refer the reader to Fan and Yao (2003) for the implementation of (6).

We can now formally test the hypothesis, $H_{0}$, that hedging does not take place at day $i$. Whenever the observed $V_{i}^{\text {sell }}$ is large enough, say above the $95 \%$ quantile of the predicted distribution of $V_{i}^{\text {sell,non-hedge }}$, it is likely that a fraction of $V_{i}^{\text {sell }}$ is due to hedging purposes. Hence we reject $H_{0}$ at day $i$ when $V_{i}^{\text {sell }}>q_{0.95}^{V_{i}^{\text {sell,non-hedge }}}$, where $q_{\alpha}^{V_{i}^{\text {sell,non-hedge }}}=\tilde{F}^{-1}\left(\alpha \mid \mathbf{X}_{i}\right)$ is the $\alpha$-quantile of the predicted distribution of $V_{i}^{\text {sell,non-hedge }}$ estimated using (6). The separate appendix shows that the power of the test depends on the conditioning variables $\mathbf{X}_{i}$ but can be as high as $20 \%$ when $V_{i}^{\text {sell }}$ is $20 \%$ larger than $V_{i}^{\text {sell,non-hedge }}$.

We remark that the null hypothesis $H_{0}$ of no hedging (when informed trades occur) concerns only long positions in newly issued call options. Short positions in the same call options do not affect our hedging detection method. It is so because the total volume of the underlying stock is divided into buyer- and seller-initiated and only the latter matters when hedging long call options. 


\subsection{Detecting Option Informed Trades Combining the Three Criteria}

Let $k_{t}$ denote the selected informed trade at day $t$ in call option $k$. The two methods to detect option informed trades can be described using the following four sets of events: $\Omega_{1}$ $:=\left\{k_{t}\right.$ such that $\left.q_{t} \leq 5 \%\right\} ; \Omega_{2}:=\left\{k_{t}\right.$ such that " $H_{0}$ : non-hedging" not rejected at day $\left.t\right\} ;$

$\Omega_{3}:=\left\{k_{t}\right.$ such that $\left.r_{t}^{\max } \geq q_{0.90}^{r_{t}^{\max }}\right\} ; \Omega_{4}:=\left\{k_{t}\right.$ such that $\left.G_{t} \geq q_{0.98}^{G_{t}}\right\}$. The first method detects an informed option trade when it belongs to the first two sets, i.e., $k_{t} \in \Omega_{1} \cap \Omega_{2}$. According to the second method an option trade is informed when it belongs to all four sets, i.e., $k_{t} \in \Omega_{1} \cap \Omega_{2} \cap \Omega_{3} \cap \Omega_{4}$.

\section{Data}

To keep the empirical analysis manageable, we focus on three main sectors, i.e., banking, insurance, and airline, and within each sector we consider some of the main companies. In addition, we also consider a number of randomly selected companies from other sectors, such as Coca-cola and Philip Morris, to broaden our empirical analysis.

We organize our dataset in two parts. The first part includes only put options, the second part put and call options.

The first part of our dataset includes 14 companies from airline, banking and various other sectors. The list of companies includes: American Airlines (AMR), United Airlines (UAL), Delta Air Lines (DAL), Boeing (BA) and KLM for the airline sector; Bank of America (BAC), Citigroup (C), J.P. Morgan (JPM), Merrill Lynch (MER) and Morgan Stanley (MWD) for the banking sector; and AT\&T (ATT), Coca-Cola (KO), Hewlett Packard (HP), and Philip Morris (MO) for the remaining sectors. Options data are from the Chicago Board 
Options Exchange (CBOE) as provided by OptionMetrics. The dataset includes the daily cross-section of available put options for each company from January 1996 to April 2006 and amounts to about 2.1 million of options. Options data for DAL and KLM were available for somewhat shorter periods. Stock prices are downloaded from OptionMetrics as well to avoid non-synchronicity issues and are adjusted for stock splits and spin-offs using information from the CRSP database. Intraday transaction prices and volumes for each underlying stock price are from NYSE's Trade and Quote (TAQ) database. This database consists of several millions of records for each stock and is necessary to classify trading volumes in buyer- and seller-initiated in order to complete the analysis related to the hedging criterion. Discrepancies among datasets have been carefully taken into account when merging databases. ${ }^{6}$ Additionally, we analyze put options on 3 European companies, Swiss Re, Munich Re and EADS, using daily data from the EUREX provided by Deutsche Bank.

The second part of our dataset includes 19 companies from the banking and insurance sectors. Put and call options data are from January 1996 to September 2009, covering the recent financial crisis, and amounts to about 7.5 million options. The list of American companies includes: American International Group (AIG), Bank of America Corporation (BAC), Bear Stearns Corporation (BSC), Citigroup (C), Fannie Mae (FNM), Freddie Mac (FRE), Goldman Sachs (GS), J.P. Morgan (JPM), Lehman Brothers (LEH), Merrill Lynch (MER), Morgan Stanley (MS), Wachovia Bank (WB) and Wells Fargo Company (WFC). Most of these companies belong to the list of banks which were bailed out and, in which,

\footnotetext{
${ }^{6}$ For example data for J.P. Morgan from OptionMetrics and TAQ do not match. Whereas the stock volume reported in OptionMetrics for the years 1996-2000 is given by the sum of the volume of Chase Manhattan Corporation and J.P. Morgan \& Co. (Chase Manhattan Corporation acquired J.P. Morgan \& Co. in 2000), TAQ only reports the volume of J.P. Morgan \& Co. Same issue was found for BankAmerica Corporation and NationsBank Corporation, whose merger took place in 1998 under the new name of Bank of America Corporation.
} 
the American Treasury Department invested approximately $\$ 200$ billion through its Capital Purchase Program in an effort to bolster capital and support new lending. Options and stock data are from the same databases as before, namely CBOE, TAQ, and CRSP. Furthermore we analyze 6 European banks: UBS, Credit Suisse Group (CS) and Deutsche Bank (DBK) whose options are traded on EUREX, and Societé Générale (GL), HSBC (HSB) and BNP Paribas $(\mathrm{BN})$ with options listed on Euronext. Options data as well as intraday transaction prices and volumes for the underlying stock are obtained from EUREX provided by Deutsche Bank, and from EURONEXT provided by NYSE Euronext database. All analyzed options are American style.

\section{Empirical Results}

The two proposed methods to detect option informed trades are applied to the companies listed in the previous section. The first method, which relies only on ex-ante information, aims at detecting informed trades as soon as they take place. On average, less than $0.1 \%$ of the total analyzed trades belongs to the set $\Omega_{1} \cap \Omega_{2}$ defined in Section 3.4. As an example for AMR our first method detects 141 option informed trades, the total number of analyzed options being more than 137,000 . This suggests that already the ex-ante method can be quite effective in signaling informed trades.

The second method, which relies also on ex-post information, selects a significantly smaller number of option informed trades. For example, only 5 informed trades are detected for AMR. Importantly, the empirical patterns of option informed trades based on the two methods are roughly the same. For example, both methods suggest that most in- 
formed trades for AMR occur before an acquisition announcement in May 2000 and the 9/11 terrorist attacks.

Due to space constraints we can only report the details of transactions selected by the expost method. The separate appendix reports a detailed analysis of various detected option informed trades.

Analyzing the first part of our dataset, 37 transactions on the CBOE have been identified as belonging to the set $\Omega_{1} \cap \Omega_{2} \cap \Omega_{3} \cap \Omega_{4}$ defined in Section 3.4. Nearly all the detected events can be assigned to one of the following three event categories: merger and acquisition (M\&A) announcements, 6 transactions; quarterly financial/earnings related statements, 14 transactions; and the terrorist attacks of September 11th, 13 transactions. 4 transactions could not be identified.

4 informed trades around M\&A announcements are detected in the airline sector. These option trades have underlying stock American Airlines and United Airlines. 3 informed trades took place on May 10th and 11th, 2000, two weeks before UAL's acquisition of US Airways was announced. ${ }^{7}$ Another informed trade took place on January 9th, 2003 with underlying Delta Air Lines, a few weeks before a public announcement on January 21st, 2003 related to the planned alliance among Delta, Northwest and Continental. In both cases, the underlying assets crashed at the public announcements, generating large gains $(\$ 3$ and $\$ 1$ million, respectively) through the exercise of these put options.

\footnotetext{
${ }^{7}$ As reported in the New York Times edition of May 25th, 2000, AMR was considered the company most threatened by the merger, explaining therefore the $17 \%$ drop in its stock in the days after the public announcement. According to James Goodwin, chairman and chief executive of UAL, two major hurdles would challenge UAL: "the first is to get US Airways shareholders to approve this transaction. [The second] is the regulatory work, which revolves around the Department of Transportation, the Department of Justice and the European Union". The skepticism on Wall Street was immediately reflected on UAL shares which declined $\$ 7.19$ to $\$ 53.19$ on the announcement day.
} 
In the airline sector 8 out of 15 of the selected transactions can be traced back to the terrorist attacks of 9/11. Companies like American Airlines, United Airlines, Boeing and to a lesser extent Delta Air Lines and KLM seem to have been targets for informed trading activities in the period leading up to the attacks. The number of new put options issued during that period is statistically high and the total gains $G_{t}$ realized by exercising these options amount to more than $\$ 16$ million. These findings support the evidence in Poteshman (2006) who also documents unusual activities in the option market before the terrorist attacks. The separate appendix discusses in details our detected option informed trades before 9/11.

In the banking sector 14 informed trading activities are detected, 6 related to quarterly financial/earnings announcements, 5 to the terrorist attacks of September 11th, and 3 not identified. For example the number of put options with underlying stock Bank of America, Citigroup, J.P. Morgan and Merrill Lynch issued in the days before the terrorist attacks was also at an unusually high level. The realized gains from such trading strategies are around $\$ 11$ million.

The last set of companies we analyze includes AT\&T, Coca Cola, Hewlett Packard and Philip Morris. 2 informed trades occurred before the announcement of the M\&A deal between Coca Cola and Procter\&Gamble announced on February 21st, 2001 (leading to gains of more than $\$ 2$ million), and 5 transactions preceding the publication of quarterly financial/earnings statements. News related to earnings shortfalls, unexpected drops in sales and production scale backs are the most common in this last category. For example 3 informed trades in put options with underlying Philip Morris stock are detected. These trades took place a few days before three separate legal cases against the company seeking a total amount of more than $\$ 50$ million in damages for smokers' deaths and inoperable lung cancer. The realized 
gains amounted to more than $\$ 10$ million. Perhaps as expected, no informed option trade is detected with underlying the previous companies in the days leading up to the terrorist attacks of September 11th. Tables 1 and 2 provide further details on option informed trades for the airline sector. To save space, corresponding tables for the banking sector and the last group of companies are collected in the separate appendix.

The second part of our dataset focuses on the banking and insurance sectors. To save space the empirical results are collected in the separate appendix. Although the sample period spans almost 15 years, from January 1996 to September 2009, the vast majority of detected informed trades occur during the Subprime crisis 2007-2009. Large movements in underlying stocks lead relatively quickly to net profits of more than $\$ 1$ million through option trading. Those profits are generally larger than the ones calculated in the first part of our dataset. Due to the rapid collapse of the financial system, the number of corporate and governmental decisions made has sharply increased, giving rise to numerous potential information leakages and informed trading activities.

To provide further insights on option informed trading, below we discuss in detail the case of an acquisition announcement in the U.S. airline sector in May 2000. Additional cases are discussed in the separate appendix.

The ex-post method detects two put option informed trades on May 10th and 11th, 2000. They involved AMR and UAL. On May 10th and 11th, the number of options issued with strike $\$ 35$ and maturity June 2000 with underlying AMR is very large: 3,374 on May 10th and 5,720 the day after (at 99.7\% and 99.9\% quantile of their two-year empirical distributions, respectively). These transactions correspond to those which exhibit the strongest increments in open interest during a span of five years; see upper left graph in Figure 1 and Figure 2. 
On May 10th, the underlying stock had a value of $\$ 35.50$ and the selected put was traded at $\$ 2.25$. For UAL 2,505 put option contracts (at $98.7 \%$ quantile of its two-year empirical distribution) with strike $\$ 65$ and the same maturity as those of AMR were issued on May 11th at the price of $\$ 5.25$ when the underlying had a value of $\$ 61.50$. The market conditions under which such transactions took place are stable. For example the average return of the stock the week before is, in both cases, positive and less than $0.5 \%$.

The days of the drop in the underlying stock are May 24th and May 25th, 2000, with the first day corresponding to the public announcement of United Airline's regarding a $\$ 4.3$ billion acquisition of US Airways. As reported in the May 25th, 2000 edition of the New York Times, "shares of UAL and those of its main rivals crashed" (for details see Footnote 7). The stock price of AMR dropped to $\$ 27.13$ ( $-23.59 \%$ of value losses when compared to the stock price on May 11th) increasing the value of the put options to $\$ 7.88$ (resulting in a return of $250 \%$ in two trading weeks). The same impact can be found for UAL: the stock price after the public announcement dropped to $\$ 52.50$ ( $-14.63 \%$ when compared to the value on May 11th) raising the put's value to $\$ 12.63$ (corresponding to a return of $140 \%$ in two trading weeks). In the case of AMR, the decline in the underlying stock can be seen in Figure 2, where the option return largely increased.

On the day of the public announcement 4,735 put options of AMR were exercised; see Figure 2. After this large decrement in open interest, 1,494 and 1,376 additional put options were exercised in the following two days respectively (reflected in additional drops in open interests in Figure 2). The unusual increments in open interest observed on May 10th and May 11th are therefore off set by the exercise of options when the underlying crashed. The corresponding gains $G_{t}$ from this strategy are more than $\$ 1.6$ million within two trading 
weeks. These are graphically shown in the lower graph in Figure 1, from which we can see how fast these gains were realized. In the case of UAL similar conclusions can be reached; see Tables 1 and 2. Based on these trades, a total gain of almost $\$ 3$ million was realized within a few trading weeks using options with underlying AMR and UAL. The non-hedging hypothesis cannot be rejected suggesting that such trades are unhedged option positions.

\section{Controlling False Discoveries in Option Informed Trades}

Any statistical method can generate false discoveries in informed trades. In other words, the probability that an option trade can satisfy various criteria simply by chance is not zero. Controlling for false discovery is then an important task which allows to separate truly informed traders with high gains from uninformed traders which luckily achieved also high gains. To separate the two groups of traders we use a multiple hypothesis testing technique. Barras, Scaillet, and Wermers (2010) adopted a similar approach to discriminate between skilled and lucky mutual fund managers based on fund performance.

Suppose we observe option returns generated by $M$ traders characterized by different degrees of information, ranging from highly accurate private information to no information (or possibly even misleading information). Let $\pi_{0}$ denote the fraction of uninformed traders and $\delta_{m}, m=1, \ldots, M$, the expected return generated by trader $m$. Under the null hypothesis all option traders are uninformed. Formally, this multiple hypothesis reads $H_{0, m}: \delta_{m}=$ $0, m=1, \ldots, M$. Each hypothesis is tested at significance level $\gamma$ (e.g., 10\%) using a twoside $t$-statistic, i.e., $H_{0, m}$ is rejected when the corresponding $t$-statistic is either below the 5th or above the 95 th percentiles of its distribution under $H_{0, m}$. When the null hypothesis is 
true, all $p$-values based on $t$-statistics are uniformly distributed between 0 and 1 . When the null hypothesis is not true, large option returns and corresponding low $p$-values are generated by both informed and lucky traders. Under such alternative hypothesis, denote $E\left[S_{\gamma}^{+}\right]$the expected fraction of $p$-values below $\gamma / 2$ corresponding to positive and significant $t$-statistics. The key step is to adjust $E\left[S_{\gamma}^{+}\right]$for the presence of lucky traders. The expected fraction of truly informed traders is $E\left[T_{\gamma}^{+}\right]=E\left[S_{\gamma}^{+}\right]-\pi_{0} \gamma / 2 .^{8}$ The last step is the estimation of $\pi_{0}$. Intuitively, large $p$-values correspond to estimated $\delta_{m}$ not statistically away from zero and hence generated by uninformed traders. The fraction of $p$-values above a certain threshold $\lambda$ is extrapolated over the interval $[0,1]$. Multiplying this fraction of $p$-values by $1 /(1-\lambda)$ provides an estimate of $\pi_{0}$. This estimation approach has been developed by Storey (2002); see, e.g., Romano, Shaikh, and Wolf (2008) for a review. We choose $\lambda$ using the data-driven approach in Barras, Scaillet, and Wermers (2010). The observed fraction of positive and significant $t$-statistics provides an unbiased estimate of $E\left[S_{\gamma}^{+}\right]$.

Obviously, we do not observe option returns achieved by traders with various degrees of private information. Consistently with our detection method, we use the historical probability $q_{t}$ of observing unusual increments in open interest and volume, as well as high gains, as a proxy for private information. The working assumption is that the smaller such probability, the higher the degree of private information of the option trader.

For every underlying asset, for every day $t$, and for every option trade $k=1, \ldots, K_{t}$ in our sample, we compute the historical probability $q_{t}^{k}$ as in (2) of observing an increment $\Delta O I_{t}^{k}$ in open interest and distance $Z_{t}^{k}:=\left(V_{t}^{k}-\Delta O I_{t}^{k}\right)$ between trading volume and increment in open

\footnotetext{
${ }^{8} \mathrm{As}$ under the null hypothesis all traders are uninformed, i.e., $\pi_{0}=1$, and half the size of the test $\gamma / 2=E\left[S_{\gamma}^{+}\right]$, the expected fraction of truly informed traders is $E\left[T_{\gamma}^{+}\right]=0$.
} 
interest, and high gains as in (5). By definition, the probability $q_{t}^{k}$ lies in the interval $[0,1]$. We sort in ascending order all $q_{t}^{k}$ and divide such unit interval into $M=1,000$ subintervals $I_{1}, \ldots, I_{M}$ such that in every subinterval the same number of $q_{t}^{k}$ is available. Then we group all option trades $q_{t}^{k}$ and corresponding returns $r_{t}^{k}$ according to which subinterval $I_{m}$ they belong. This procedure allows us to construct $M$ hypothetical option traders, each one of them characterized by a different degree of private information and option returns. In subintervals $I_{m}, m=1, \ldots, M$, the lower $m$, the more informed the trader is, and therefore, the more likely it is that she will generate large positive return $r_{t}^{k}$. Within each subinterval $I_{m}$, we regress unadjusted annualized option returns $r_{t}^{k}$ on a subinterval-specific constant $\delta_{m}$, estimating the expected return of trader $m .^{9}$

As an example Figure 3 shows estimated $\delta_{m}$ for American Airlines. Estimates for the remaining companies are similar. The lower $m$, the higher the estimated $\delta_{m}$, and the relation is nearly monotonic. Moreover, for small $m$, the estimated $\delta_{m}$ are positive and significant, whereas for increasing $m, \delta_{m}$ becomes statistically indistinguishable from zero. This finding suggests that $q_{t}^{k}$ is a sensible proxy for private information in option trades.

We briefly discuss now the estimates of false discovery rates for American Airlines and Citigroup. For the remaining companies, similar results have been found. Because of space constraints, figures and tables are not reported but available upon request from the authors. For AMR, the total number of analyzed option trades amounts at 137,000, implying that each regression coefficient $\delta_{m}$ has been computed by relaying on 137 option returns $r_{t}^{k}$. The

\footnotetext{
${ }^{9}$ In the regression, we do not adjust option returns for market return or any other variable because the focus is on the ability of the option trader to generate large returns, including those returns based on predicting future market or other variable movements. In order to make least squares estimation more robust we exclude negative returns below the $5 \%$ empirical quantile. The impact of winsorizing on the false discovery rate is virtually negligible.
} 
expected fraction of truly informed traders has been estimated to be $E\left[T^{+}\right]=9.8 \%$ (with standard error $1.15 \%$, optimal $\lambda=0.65$, and $\gamma=0.11$ ), corresponding to 98 traders. As the ex-ante procedure detects 141 trades for AMR, the test result suggests that some of these trades may be actually uninformed. In contrast, the ex-post procedure is more conservative and detects only 5 informed trades, which implies that these trades are most likely informed. For the case of Citigroup, option trades amount at 246,000 and the estimated fraction of truly informed traders $E\left[T^{+}\right]=10.6 \%$ (with standard error $1.09 \%$, optimal $\lambda=0.612$, and $\gamma$ $=0.07)$, corresponding to 106 traders. The ex-post method detects only 2 informed option trades. Thus also in this case the detection procedure is conservative and detected trades are most likely informed. For the remaining companies we found similar results.

Finally, to assess the ability of the FDR test at controlling for false discoveries, we run the following experiment. ${ }^{10}$ We identify the major natural disasters, such as floods, hurricanes, volcanic eruptions, oil spills, and earthquakes from 2000 to 2011. As the exact timing of the event is in principle unpredictable, this should rule out informed trades. Then, we consider all the option trades over the two weeks prior to the relevant event in the companies that were affected ex-post by the event. Given the setup, no option trade should be classified as informed.

Table 3 provides the list of natural disasters and affected companies, as well as the rationale for including these companies. For example we consider British Petroleum before the oil spill in the U.S. Gulf Coast in 2010. The list of companies is constrained by option data availability, i.e., open interest and volume for individual options. Computing $q_{t}$ as in (2) and considering $q_{t}<5 \%$, a very small number of suspicious option trades is detected

\footnotetext{
${ }^{10}$ We thank an anonymous referee for suggesting this experiment.
} 
over the two weeks prior to a natural disaster. When applying the FDR test all such trades are attributed to luck, confirming the validity of our procedure. Detailed test results are available from the authors upon request.

\section{Robustness Checks}

The input parameters in our detection procedure are: the length $N$ of the estimation window, chosen to be $N=500$ trading days, used for the computation of the ex-ante probability $q_{t}$,

the conditional distribution of $V_{t}^{\text {sell,non-hedge }}$, and the quantiles $q_{\alpha}^{r_{t}^{\max }}$ and $q_{\alpha^{\prime}}^{G_{t}}$; the time period after the transaction day used for the computation of $r_{t}^{\max }$, chosen to be 10 trading days; the time horizon $\tau_{t}$ used for the calculation of the gains $G_{t}$, chosen to be 30 trading days; the quantile levels $\alpha$ and $\alpha^{\prime}$ in $q_{\alpha}^{r_{t}^{\max }}$ and $q_{\alpha^{\prime}}^{G_{t}}$ used for the computation of the sets $\Omega_{3}$ and $\Omega_{4}$, chosen to be $\alpha=90 \%$ and $\alpha^{\prime}=98 \%$; the probability level used to select trades belonging to the set $\Omega_{1}$, chosen to be $5 \%$. In what follows we set the input parameters to different values and we repeat all previous analysis for all companies. To save space we report only some of the results and for a few companies giving a sense of the robustness of our results. Additional results are available from the authors upon request.

When varying the length of the estimation window $N$ between 200 and 1,000, (all other parameters being unchanged) the number of selected transactions does not change significantly. For example in the case of AMR, we selected 5 informed trades when considering the last two trading years ( $N=500$ days); for $N \in[200,1000]$ the number of detected informed trades ranges between 4 and 6 ; for UAL, we detected 2 informed trades when considering the last two trading years $(N=500$ days $)$; this number remains unchanged with respect to the 
original choice for $N>450$ and decreases by one when $N \in[200,450]$. In the case of BAC and AT\&T, the deviation from the original number of selected trades is less than 2. With respect to the choice of the time period used for the computation of $r_{t}^{\max }$ and $\tau_{t}$, our results are also robust. We let the length of the first period vary in the range $[1,30]$ days and the second one in $[1,40]$ days. In the case of AMR, the number of transactions ranges from 2 to 8, being therefore centered around the original number and with a small deviation from it. For UAL, the corresponding range is from 1 to 4, for BAC from 2 to 8 and for AT\&T from 1 to 6 . The number of detected trades is obviously a decreasing function of $\alpha$ and $\alpha^{\prime}$ (all other parameters being unchanged). In the case of AMR, when $\left\{\alpha, \alpha^{\prime}\right\} \in[0.85,0.95] \times[0.96,1]$, the number of transactions selected does not exceed 15. For UAL, the number of selected trades varies between 1 and 10, for BAC between 5 and 25, and for AT\&T between 1 and 18 . Finally, with respect to the probability level used to determine the set $\Omega_{1}$, our findings are very robust as well. When increasing the level from $1 \%$ to $10 \%$, the number of trades selected for AMR varies between 1 and 6; for UAL it ranges between 2 to 4, for BAC and AT\&T from 1 to 7 . We simultaneously changed several parameters and found that the number of detected transactions does not change significantly and in almost all cases in steps of one. We recall that approximately 9.6 million of options are analyzed. Based on these results, we conclude that our findings are robust.

\section{Conclusion}

We develop two statistical methods to detect informed trading activities in the options markets. We apply these methods to a large dataset uncovering various features of option in- 
formed trading. Detected option informed trades tend to cluster prior to certain events (such as acquisition or financial disruption announcements), involve often liquid options (which is consistent with informed traders attempting not to immediately reveal their private signals), generate easily large gains exceeding millions (which is likely a conservative estimate), and are not contemporaneously reflected in the underlying stock price (which has implications for trading strategies). These findings are not driven by false discoveries in informed trades which are controlled using a multiple hypothesis testing technique.

Our findings have policy, pricing, and market efficiency implications. If some of the detected informed trades are indeed illegal, for example originated by insiders, it can be optimal for regulators to expend relatively more monitoring efforts on the options markets. Pricing models should account for all relevant current information. However nearly all option prices (and underlying assets) involved in informed trades do not show any specific reaction to large increments in open interest and volume. The strong movements in detected options are simply due to subsequent large movements in stock prices originated by specific firm news. Finally, our findings suggest that certain increments in open interest and volume may predict large price movements and simple option trading strategies can generate large returns. Further research is necessary to assess whether those returns are truly abnormal, questioning market efficiency, or rather reflect compensation for risk factors.

\section{Acknowledgements}

For helpful comments we thank Peter Carr, Fulvio Corsi, Rüdiger Fahlenbrach, Ramo Gençay, Rajna Gibson, Michel Habib, Michael Magill, Richard Meier, Claudia Ravanelli, Anna Reshetar, and Alex Wagner. We thank Felix Fattinger for superb research assistance. 
The views expressed here are not necessarily those of UBS AG. Financial support by the Swiss National Science Foundation NCCR-FINRISK and the Research Priority Program "Finance and Financial Markets" (University of Zurich) is gratefully acknowledged. 
Summary of Airline Sector Jan 1996 - Apr 2006

\begin{tabular}{|c|c|c|c|c|c|c|c|c|c|c|c|c|c|c|c|c|}
\hline Day & \multicolumn{15}{|c|}{ American Airlines (AMR) Jan 1996 - Apr 2006} & $1-p_{t}$ \\
\hline 10 May 00 & 10821216 & 1.01 & 38 & 20 & 3374 & $99.7 \%$ & 3378 & 3290 & $106 \%$ & 9 & 906,763 & 11 & $100 \%$ & 0.002 & 0.286 & 0.998 \\
\hline 11 May 00 & 10821216 & 1.02 & 37 & 3394 & 5720 & $99.9 \%$ & 5442 & 5320 & $98 \%$ & 10 & $1,647,844$ & 11 & $100 \%$ & 0.002 & 0.349 & 0.998 \\
\hline 31 Aug 01 & 20399554 & 0.91 & 22 & 96 & 473 & $95.7 \%$ & 571 & 500 & $455 \%$ & 7 & 662,200 & 11 & $100 \%$ & 0.016 & 0.645 & 0.984 \\
\hline 10 Sep 01 & 20428354 & 0.99 & 40 & 258 & 1312 & $98.5 \%$ & 1701 & 1535 & $453 \%$ & 2 & $1,179,171$ & 26 & $100 \%$ & 0.012 & 0.096 & 0.998 \\
\hline 24 Aug 05 & 27240699 & 0.97 & 24 & 1338 & 4378 & $93.5 \%$ & 8395 & 5319 & $163 \%$ & 8 & 575,105 & 17 & $100 \%$ & 0.048 & 0.123 & 0.952 \\
\hline \multicolumn{17}{|c|}{ United Airlines (UAL) Jan 1996 - Jan 2003} \\
\hline 11 Мay 00 & 11332850 & 0.95 & 37 & 35 & 2505 & $98.7 \%$ & 2534 & 2505 & $132 \%$ & 10 & $1,156,313$ & 26 & $100 \%$ & 0.002 & 0.373 & 0.998 \\
\hline 6 Sep 01 & 20444473 & 1.06 & 44 & 21 & 1494 & $96.3 \%$ & 1189 & 2000 & $1322 \%$ & 7 & $1,980,387$ & 28 & $100 \%$ & 0.030 & 0.165 & 0.998 \\
\hline \multicolumn{17}{|c|}{ Delta Air Lines (DAL) Jan 1996 - May 2005} \\
\hline *1 Oct 98 & 10904865 & 1.01 & 16 & 140 & 974 & $97.7 \%$ & 483 & 924 & $261 \%$ & 6 & $\overline{537,594}$ & 12 & $100 \%$ & 0.016 & 0.000 & 0.996 \\
\hline 29 Aug 01 & 20402792 & 0.98 & 24 & 1061 & 202 & $89.7 \%$ & 224 & 215 & $1033 \%$ & 9 & 328,200 & 13 & $100 \%$ & 0.044 & 0.528 & 0.998 \\
\hline 19 Sep 02 & 20718332 & 0.99 & 30 & 275 & 1728 & 98. & 550 & 1867 & $132 \%$ & 7 & 331,676 & 22 & $100 \%$ & 0.004 & 0.190 & 0.998 \\
\hline 9 Jan 03 & 21350972 & 1.10 & 44 & 274 & 3933 & $99.7 \%$ & 4347 & 4512 & $112 \%$ & 9 & $1,054,217$ & 30 & $100 \%$ & 0.002 & 0.065 & 0.998 \\
\hline \multicolumn{17}{|c|}{ Boeing (BA) Jan 1996 - Apr 2006} \\
\hline 24 Nov 98 & 10948064 & 0.99 & 53 & 3758 & 1047 & $93.5 \%$ & 1285 & 1535 & $467 \%$ & 7 & 883,413 & 24 & $100 \%$ & 0.040 & 0.481 & 0.996 \\
\hline 29 Aug 01 & 20400312 & 0.92 & 24 & 1019 & 2828 & $96.7 \%$ & 3523 & 3805 & $382 \%$ & 10 & $1,972,534$ & 8 & $100 \%$ & 0.028 & 0.252 & 0.998 \\
\hline 5 Sep 01 & 20429078 & 1.01 & 45 & 472 & 1499 & $92.1 \%$ & 2538 & 1861 & $890 \%$ & 8 & $1,805,929$ & 22 & $100 \%$ & 0.048 & 0.085 & 0.998 \\
\hline 6 Sep 01 & 11839316 & 0.75 & 135 & 13228 & 7105 & $99.3 \%$ & 13817 & 7108 & $118 \%$ & 7 & $2,704,701$ & 3 & $100 \%$ & 0.006 & 0.150 & 0.998 \\
\hline *7 Sep 01 & 20400311 & 0.90 & 15 & 7995 & 4179 & $98.5 \%$ & 4887 & 5675 & $306 \%$ & 6 & $5,775,710$ & 7 & $100 \%$ & 0.016 & 0.000 & 0.998 \\
\hline *17 Sep 01 & 20400309 & 0.90 & 5 & 116 & 5026 & $98.9 \%$ & 2704 & 5412 & $124 \%$ & 4 & $2,663,780$ & 5 & $100 \%$ & 0.010 & 0.000 & 0.998 \\
\hline \multicolumn{17}{|c|}{ KLM Jan 1996 - Nov 2001} \\
\hline 5 Sep 01 & 20296159 & 0.91 & 17 & 3 & 100 & $99.3 \%$ & 34 & 100 & $467 \%$ & 9 & 53976 & 9 & $100 \%$ & 0.006 & 0.368 & 0.998 \\
\hline
\end{tabular}

Table 1: This table shows day on which the transaction took place, Day; identification number of the put option, $I d$; moneyness, i.e., stock price divided by strike price, $S / K$; time-to-maturity, $\tau$; level of open interest the day before the informed trade, $O I_{t-1}$; increment in open interest from day $t-1$ to day $t, \Delta O I_{t}$; its quantile with respect to its empirical distribution computed over the last two years, $q_{t}^{\Delta O I}$; total increment in open interest, i.e., when considering all the available options at day $t$ and not only the ones which had the highest increment, $\Delta O I_{t}^{\text {tot}}$; corresponding volume, Vol ${ }_{t}$; maximum return realized by the selected option during the two-week period following the transaction day, $r_{t}^{\max }$; number of days between transaction day $t$ and when this maximum return occurs, $\tau_{2}$; gains realized through the exercise of the option issued at time $t$ as in (4), $G_{t}$; minimum between the number of days (starting from the transaction day) needed for the exercise of $\Delta O I_{t}$ and 30 days, $\tau_{3}$; percentage of $\Delta O I_{t}$ exercised within the first 30 days after the transaction, \%ex.; ex-ante probability in $(2), q_{t} ; p$-value of the hypothesis that delta hedging does not take place at time $t, p$-value; proxy for the probability of informed trading in (5), $1-p_{t}$. 
Summary of Airline Sector Jan 1996 - Apr 2006

\begin{tabular}{|c|c|c|c|}
\hline Day of transaction & Market condition & Return & $\begin{array}{l}\text { Crash in stock } \\
\text { American Airlines (AMR) Jan } 1996-\text { Apr } 2006\end{array}$ \\
\hline 10 May 00 & $0.4 \%$ & $-17.6 \%$ & 24/25 May 00 $\quad$ Announcement 24 May 00: Airline Deal UAL's acquisition of US Airways \\
\hline 11 May 00 & $0.0 \%$ & $-17.6 \%$ & Announcement 24 May 00: Airline Deal UAL's acquisition of US Airways \\
\hline 31 Aug 01 & $-0.4 \%$ & $-39.4 \%$ & 9/11 Terrorist attacks in New York \\
\hline 10 Sep 01 & $-1.4 \%$ & $-39.4 \%$ & 9/11 Terrorist attacks in New York \\
\hline 24 Aug 05 & $0.4 \%$ & $-5.3 \%$ & $\begin{array}{l}30 \text { Aug } 05 \\
\text { August 05: Hurricane Katrina, interrupted production on the gulf coast, jet fuel prices } \uparrow \\
\text { United Airlines (UAL) Jan } \mathbf{1 9 9 6} \text { - Jan } \mathbf{2 0 0 3}\end{array}$ \\
\hline $\begin{array}{r}11 \text { May } 00 \\
6 \text { Sep } 01\end{array}$ & $\begin{array}{r}0.3 \% \\
-1.0 \%\end{array}$ & $\begin{array}{r}-12 \% \\
-43.2 \%\end{array}$ & $\begin{array}{cc}\text { 24 May 00 } & \text { Announcement 24 May 00: Airline Deal UAL's acquisition of US Airways } \\
\text { 17 Sep 01 } & 9 / 11 \text { Terrorist attacks in New York } \\
\text { Delta Air Lines (DAL) Jan } \mathbf{1 9 9 6} \text { - May } \mathbf{2 0 0 5}\end{array}$ \\
\hline $\begin{array}{r}* 1 \text { Oct } 98 \\
29 \text { Aug } 01 \\
19 \text { Sep } 02 \\
9 \text { Jan } 03\end{array}$ & $\begin{array}{r}-1.7 \% \\
0.0 \% \\
-5.2 \% \\
2.1 \%\end{array}$ & $\begin{array}{l}-11.4 \% \\
-44.6 \% \\
-24.4 \% \\
-15.7 \%\end{array}$ & $\begin{array}{l}\text { 07/08 Oct } 98 \\
\text { 17 Sep } 01 \\
\text { 27 Sep } 02 \\
\text { 21/22 Jan 03 Announcement 21 Jan 03: Restrictions on planned alliance of Delta, Northwest and Continental } \\
\text { Boeing (BA) Jan 1996 - Apr 2006 }\end{array}$ \\
\hline $\begin{array}{r}24 \text { Nov } 98 \\
29 \text { Aug } 01 \\
5 \text { Sep } 01 \\
6 \text { Sep } 01 \\
* 7 \text { Sep } 01 \\
* 17 \text { Sep } 01\end{array}$ & $\begin{array}{l}-0.2 \% \\
-0.4 \% \\
-0.8 \% \\
-0.9 \% \\
-1.9 \% \\
-5.6 \%\end{array}$ & $\begin{array}{l}-22.0 \% \\
-25.0 \% \\
-25.0 \% \\
-25.0 \% \\
-25.0 \% \\
-25.0 \%\end{array}$ & 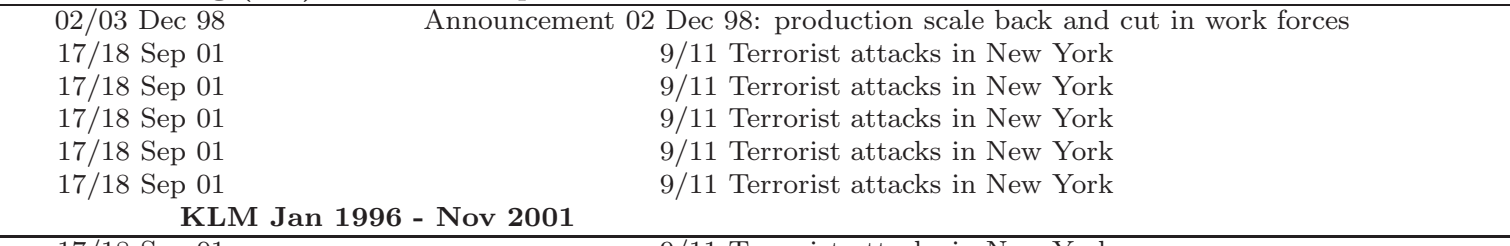 \\
\hline
\end{tabular}

Table 2: This table shows day on which the transaction took place, Day of transaction; market condition at day $t$ measured by the average return of the underlying stock during the last two trading weeks, Market condition; minimum return of the underlying stock during the two-week period following the transaction day, Return (comparable with $r_{t}^{\max }$ ); day when the underlying stock drops, Crash in stock; short description of the event and why the stock drops, Event's description. * means that the hypothesis of non-hedging can be rejected at a $5 \%$ level. 


\section{Natural Disasters and False Discoveries of Informed Trades}

\begin{tabular}{ccc}
\hline Event & Date & Company \\
Central Europe floods & 11 Aug 02 & Advanced Micro Devices \\
Hurricane Katrina & 29 Aug 05 & ExxonMobil \\
Eruptions of Eyjafjallajökull (Iceland) & 14 Apr 10 & FedEX \\
Deepwater Horizon oil spill & 20 Apr 10 & British Petroleum \\
Japan earthquake & 11 Mar 11 & British Petroleum
\end{tabular}

Table 3: This table lists some of the natural disasters that occurred between 2000 and 2011, the date of the event, and some of the companies that were affected ex-post by the event. The rationale for including the companies is the following. Central Europe floods: Advanced Micro Devices was operating a main chip fabrication plant in Dresden which was eventually only marginally affected by the floods. Hurricane Katrina: ExxonMobil was operating a major refinery near the U.S. Gulf Coast. Eruptions of Eyjafjallajökull: the International Air Transport Association imposed an air travel ban and transportation companies like FedEX were negatively affected. Deepwater Horizon oil spill: British Petroleum was responsible for the oil spill and operated the oil prospect. Japan earthquake: the earthquake has led to a fall in the oil price, which has added to pressure on British Petroleum's share price. 

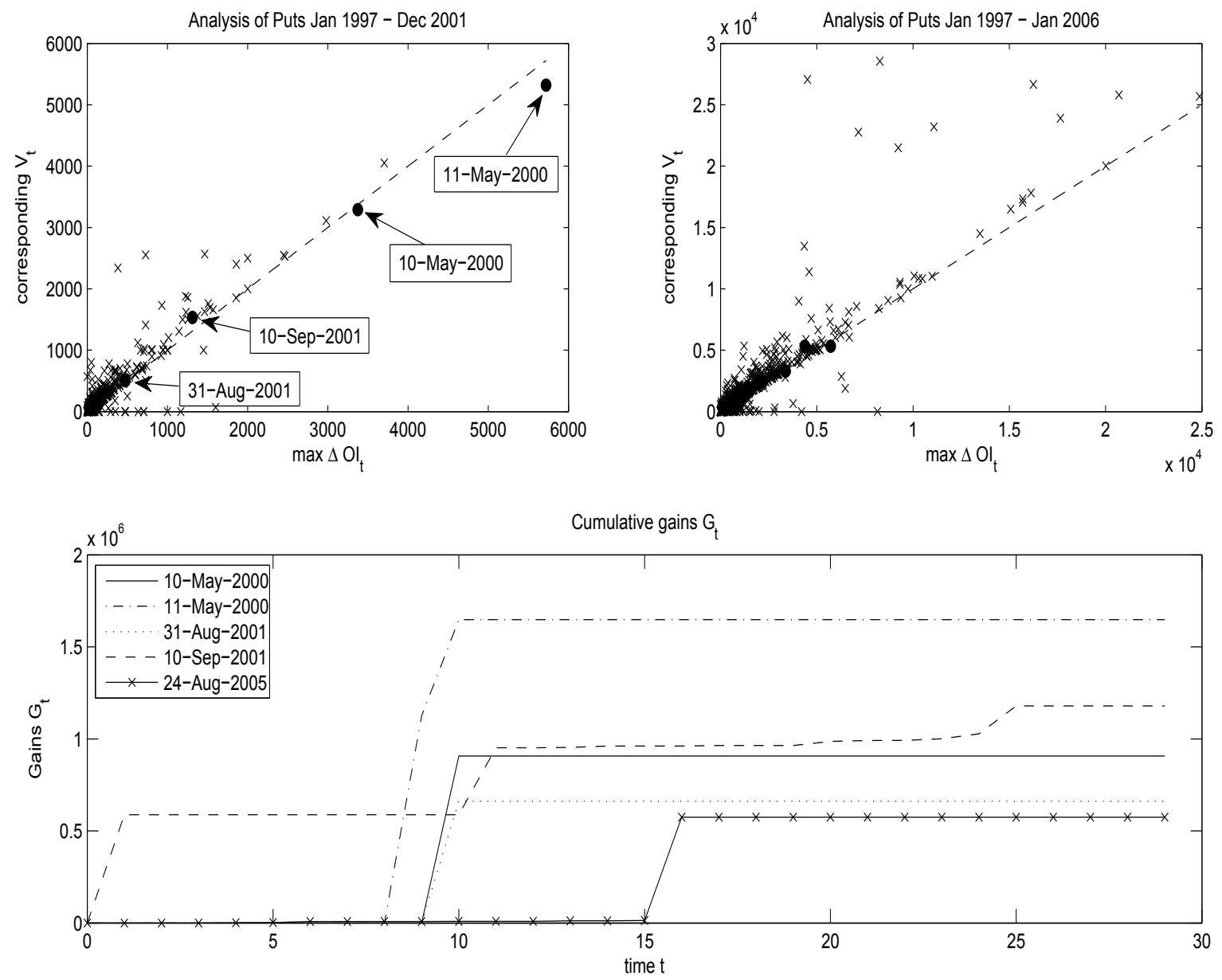

Figure 1: Upper graphs show on the x-axis maximal daily increment in open interest across all put options with underlying American Airlines (AMR), and on the y-axis the corresponding trading volume. Upper-left graph covers the period January 1997 - December 2001, upperright graphs the period January 1997 - January 2006. Lower graph shows cumulative gains $G_{t}$ in USD as in equation (4) for detected option informed trade on AMR. Gains correspond to those realized by daily exercising/selling the options. 


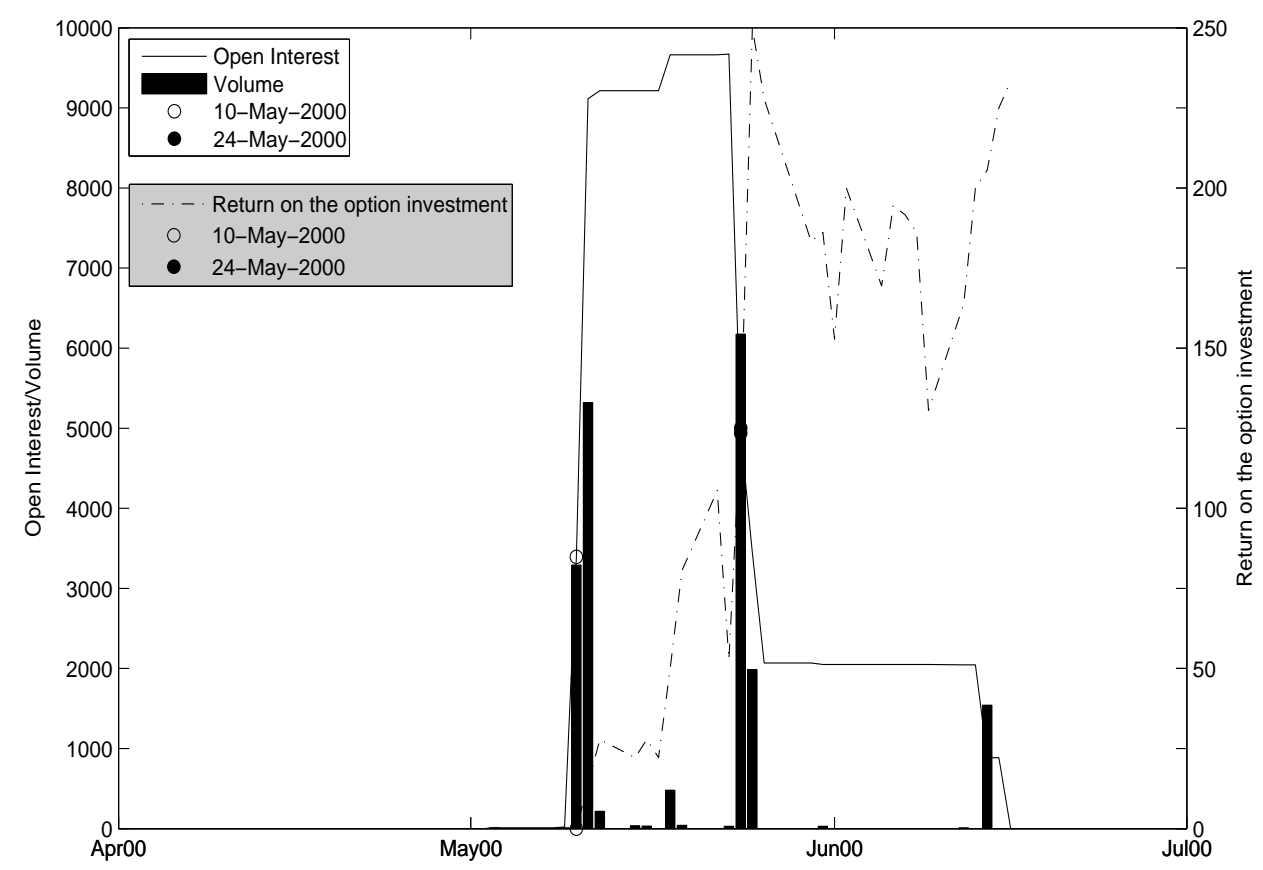

Figure 2: Selected put option for informed trading with underlying stock American Airlines (AMR) before the United Airlines (UAL) announcement of $\$ 4.3$ billion acquisition of US Airways in May 2000. The solid line shows the daily dynamic of open interest, the bars show the corresponding trading volume (left y-axis) and the dash-dot line the option return (right $y$-axis). The empty circle is the day of the transaction, the filled circle is the day of the announcement (partially covered by the highest bar). This put option had a strike of $\$ 35$ and matured at the end of June 2000. 

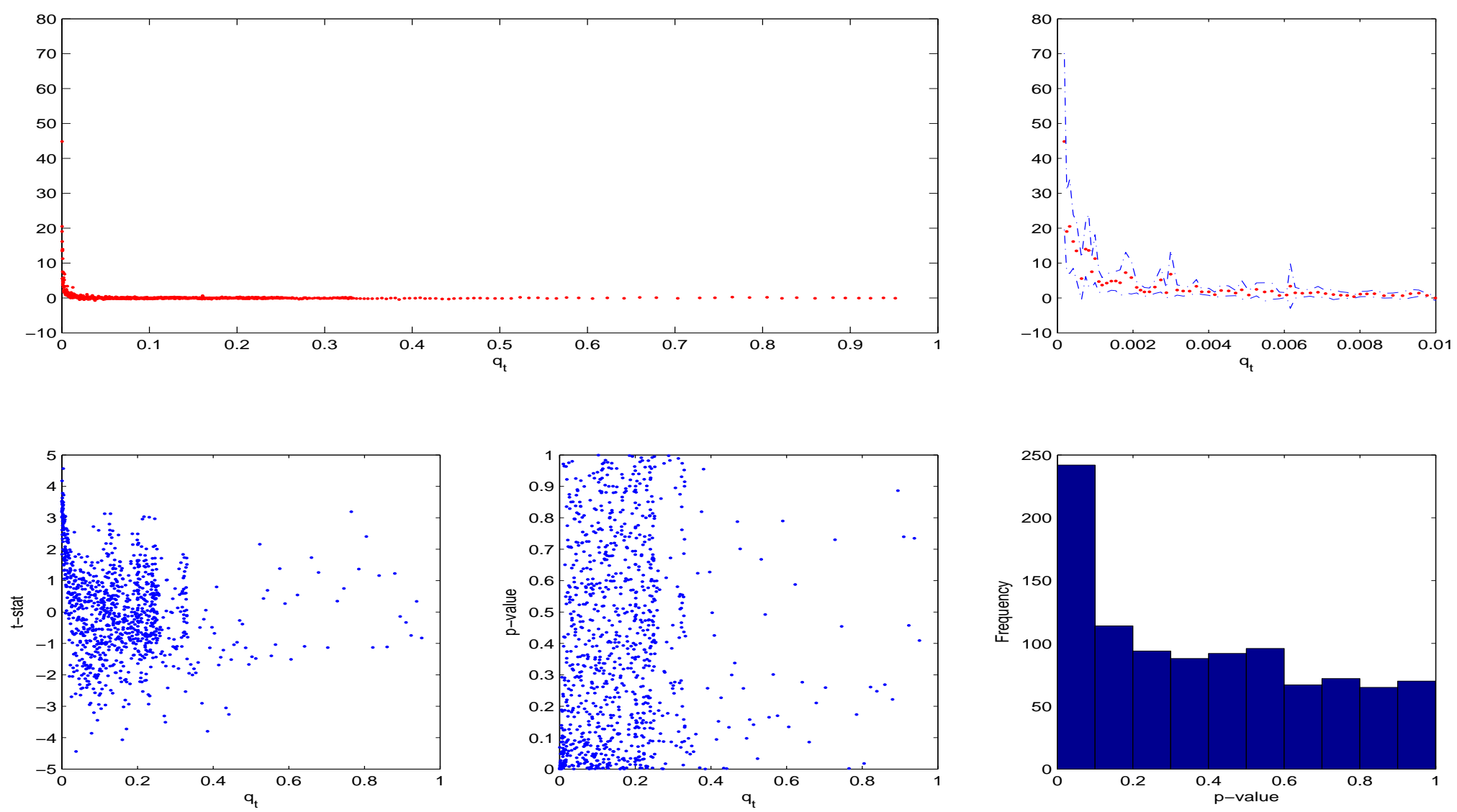

Figure 3: False Discovery Rate for American Airlines. The upper-left graph shows on the x-axis the probability $q_{t}$ (the right-end point in each subinterval $I_{m}$ ), and on the y-axis the corresponding average option returns $\delta_{m}$ associated to the $m$ th option trader. The upper-right graph shows the same quantities when $0 \leq q_{t} \leq 0.01$. Dashed-dotted lines represent $95 \%$ confidence intervals for $\delta_{m}$. The lower graphs, from left to right, show $t$-statistics of option returns associated to the $M$ option traders for the null hypothesis $H_{0}: \delta_{m}=0, m=1, \ldots, M, p$-values, and frequency histogram of $p$-values, respectively. 


\section{References}

Bali, T., and A. Hovakimian, 2009, "Volatility Spreads and Expected Stock Returns," Management Science, 55, 1797-1812.

Barras, L., O. Scaillet, and R. Wermers, 2010, "False Discoveries in Mutual Fund Performance: Measuring Luck in Estimated Alphas," Journal of Finance, 65, 179-216.

Biais, B., and P. Hillion, 1994, "Insider and Liquidity Trading in Stock and Options Markets," Review of Financial Studies, 7, 743-780.

Blume, L., D. Easley, and M. O’Hara, 1994, "Market Statistics and Technical Analysis: The Role of Volume," Journal of Finance, 49, 153-181.

Boulatov, A., T. Hendershott, and D. Livdan, 2012, "Informed Trading and Portfolio Returns," Review of Economic Studies, forthcoming.

Cao, C., Z. Chen, and J. Griffin, 2005, "Informational Content of Option Volume Prior to Takeovers," Journal of Business, 78, 1073-1109.

Chan, K., P. Chung, and H. Johnson, 1993, "Why Option Prices Lag Stock Prices: A Trading-Based Explanation," Journal of Finance, 48, 1957-1967.

Chen, J., H. Hong, and J. Stein, 2001, "Forecasting Crashes: Trading Volume, Past Returns, and Conditional Skewness in Stock Prices," Journal of Financial Economics, 61, 345-381.

Christophe, S., M. Ferri, and J. Angel, 2004, "Short-Selling Prior to Earnings Announcements," Journal of Finance, 59, 1845-1875.

Cremers, M., and D. Weibaum, 2010, "Deviations from Put-Call Parity and Stock Return Predictability," Journal of Financial and Quantitative Analysis, 45, 335-367.

Diamond, D., and R. Verrechia, 1987, "Constraints on Short-Selling and Asset Price Adjustment to Private Information," Journal of Financial Economics, 18, 277-311.

Easley, D., and M. O'Hara, 1992, "Time and the Process of Security Price Adjustment," Journal of Finance, 47, 577-605.

Easley, D., M. O'Hara, and P. Srinivas, 1998, "Option Volume and Stock Prices: Evidence on Where Informed Traders Trade," Journal of Finance, 53, 431-465.

Fan, J., and Q. Yao, 2003, Nonlinear Time Series: Nonparametric and Parametric Methods. Springer-Verlag, New York.

Gârleanu, N., L. Pedersen, and A. Poteshman, 2009, "Demand-Based Option Pricing," Review of Financial Studies, 22, 4259-4299.

Grossman, S., 1977, "The Existence of Futures Markets, Noisy Rational Expectations and Information Externalities," Review of Economic Studies, 44, 431-449. 
Hall, P., R. Wolff, and Q. Yao, 1999, "Methods for Estimating a Conditional Distribution Function," Journal of the American Statistical Association, 94, 154-163.

Hasbrouck, J., 1991, "Measuring the Information Content of Stock Trades," Journal of Finance, 46, 179-207.

Keown, A., and J. Pinkerton, 1981, "Merger announcements and Insider Trading Activity: An Empirical Investigation," Journal of Finance, 36, 855-869.

Lakonishok, J., I. Lee, N. Pearson, and A. Poteshman, 2007, "Option Market Activity," Review of Financial Studies, 20, 813-857.

Lee, C., and M. Ready, 1991, "Inferring Trade Direction from Intraday Data," Journal of Finance, 46, 733-746.

Lee, J., and C. Yi, 2001, "Trade Size and Information-Motivated Trading in the Options and Stock Markets," Journal of Financial and Quantitative Analysis, 36, 485-501.

Lee, M., B. Mucklow, and M. Ready, 1993, "Spreads, Depths, and the Impact of Earnings Information: An Intraday Analysis," Review of Financial Studies, 6, 345-374.

Manaster, S., and R. Rendleman, 1982, "Option Prices as Predictors of Equilibrium Stock Prices," Journal of Finance, 37, 1043-1057.

Pan, J., and A. Poteshman, 2006, "The Information in Option Volume for Future Stock Prices," Review of Financial Studies, 19, 871-908.

Poteshman, A., 2006, "Unusual Option Market Activity and the Terrorist Attacks of September 11, 2001," Journal of Business, 79, 1703-1726.

Romano, J., A. Shaikh, and M. Wolf, 2008, "Formalized Data Snooping on Generalized Error Rates," Econometric Theory, 24, 404-447.

Stephan, J., and R. Whaley, 1990, "Intraday Price Change and Trading Volume Relations in the Stock and Stock Option Markets," Journal of Finance, 45, 191-220.

Storey, J., 2002, "A Direct Approach to False Discovery Rates," Journal of the Royal Statistical Society, 64, 479-498.

Vijh, A., 1990, "Liquidity of the CBOE Equity Options," Journal of Finance, 45, 1157-1179.

Yan, S., 2011, "Jump Risk, Stock Returns, and Slope of Implied Volatility Smile," Journal of Financial Economics, 99, 216-233. 